\title{
HIGH GAIN COMPACT MICROSTRIP PATCH ANTENNA FOR X-BAND APPLICATIONS
}

\author{
${ }^{1}$ Mohamed AlyAboul-Dahab, ${ }^{2}$ Hussein Hamed Mahmoud Ghouz and ${ }^{3}$ Ahmed \\ Zakaria Ahmed Zaki \\ ${ }^{1,2}$ Professors in Department of Electronics and Communications \\ Arab Academy for Science, Technology \& Maritime Transport (AASTMT), Cairo, Egypt \\ ${ }^{3}$ Master students in Arab Academy for Science, (AASTMT), Cairo, Egypt
}

\begin{abstract}
This paper present a design of a Frequency Selective Surface (FSS) to improve gain and efficiency of a microstrip patch antenna operating in X-band at $10 \mathrm{GHz}$. The band-stop frequency selective surface (FSS) designed at the operating frequency of the antenna is used. FSS structure is configured as a superstrate for the microstrip patch antenna. The main goal of this paper is design a compact microstrip antenna module (microstrip patch and FSS structure). Simulation results using CST studio showed that high gain (54\% increment) and efficiency is increased to $97 \%$ have been achieved by the proposed antenna module (MS and FSS). The equivalent circuit of proposed FSS unit cell in ADS software has been evaluated and compared to simulation results (CST studio) to improve characteristics of the antenna. The proposed antenna module is extremely compact high gain and it can be used for $X$-band applications.
\end{abstract}

\section{KEYWORDS}

Compact; microstrip; frequency selective surface; X-band.

\section{INTRODUCTION}

In recent years, the demand for high gain antennas has increased for use in high-frequency and high-speed data communication. Microstrip patch antenna characterized by attractive features such as low cost and compact size, but the important problems of patch antenna are its small gain, law directivity and narrow bandwidth because of substrate dielectric has surface wave losses [1, 2], so to improve the gain and directivity became an important issue in the antenna design field. Improving bandwidth, gain and directivity can obtained by an antenna with periodic elements (FSS) [3-8]. Frequency selective surface (FSS) is a 2D planar structure consisting of a twodimensional array of slot elements in a metal sheet or an array of metal patch elements fabricated on dielectric substrate. The frequency response of FSS is determined by the shape and size of the structure in one period called a unit cell [9]. Aperture and patch screens generally give complementary frequency responses, the field is totally transmitted at the resonant frequency of the aperture while a screen comprised of patches will be nearly totally reflected at the resonant frequency of the patches [10]. Frequency selective surfaces (FSSs) have been investigated for a variety of applications such as bandpass and bandstop spatial filter [11-14], radar absorbers [1517], and artificial electromagnetic bandgap materials [18]. It can also be used as Specific Absorption Rate (SAR) [19].

In this paper, the single band frequency FSS consisting of hexagonal loop elements is used to enhance gain and efficiency of proposed compact rectangular microstrip antenna operating at 10 $\mathrm{GHz}$. However, the design of such complex structure of FSS is not easy matter due to many 
design parameters that require optimized. This paper is divided into five sections. Section 2 discuss antenna and frequency selective surface (FSS) designs. Section 3 shows result and discussion which include a parametric study of FSS cell and effect of implanting FSS to antenna. Implementation and Experimental testing of FSS and antenna is discussed in Section 4 followed by conclusion in Section 5 .

\section{ANTENNA AND PROPOSED FREQUENCY SELECTIVE SURFACE DESIGN}

\subsection{Proposed Antenna}

Proposed antenna is a conventional rectangular microstrip antenna which designed to operate at $10 \mathrm{GHz}$ in X-band. As shown in figures [1], the rectangular patch antenna is printed on $1.575 \mathrm{~mm}$ thickness ROGGER 5880 substrate with dielectric constant 2.2. A copper plate with dimensions of $40 \mathrm{~mm} \mathrm{X} 40 \mathrm{~mm}$ and thickness of $0.035 \mathrm{~mm}$ is used as the ground plane. The patch uses copper as material and the thickness of it is $0.035 \mathrm{~mm}$, the patch is symmetrically designed and the feed point lies in the central line of $3.4 \mathrm{~mm}$, a coaxial line with a characteristic impedance of $50 \mathrm{ohms}$ is used as the feed of the conventional patch antenna. The inner conductor of the coaxial line is attached on the top patch going through the dielectric substrate, and the outer conductor is shorted to the metallic plate on the other side of the patch antenna. All dimensions evaluated by using equations [1,2] as shown in table 1.

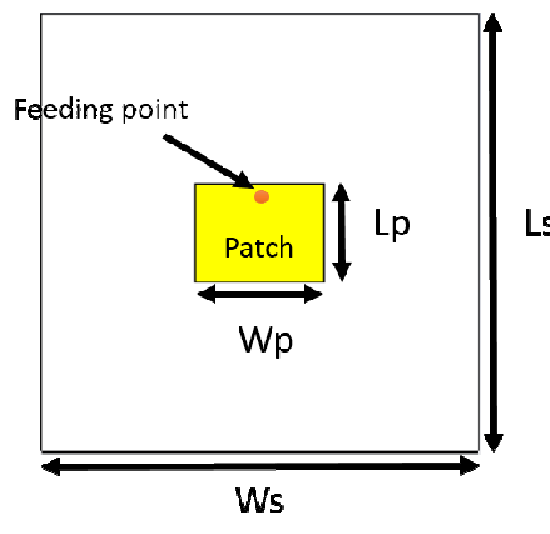

(a)

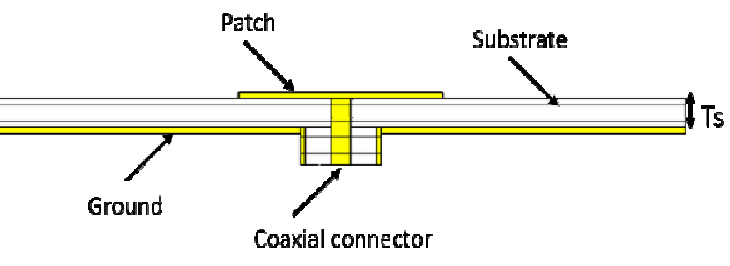

(b)

Figure 1: Antenna (a) Top view (b) Side view

Table 1. Proposed antenna parameters (MILLEMETER)

\begin{tabular}{|c|c|c|c|}
\hline \multicolumn{2}{|c|}{ Patch } & \multicolumn{2}{c|}{ Substrate } \\
\hline $\mathrm{Wp}(\mathrm{mm})$ & 11.85 & Ws $(\mathrm{mm})$ & 40 \\
\hline $\mathrm{Lp}(\mathrm{mm})$ & 9.13 & Ls $(\mathrm{mm})$ & 40 \\
\hline $\mathrm{Tp}(\mathrm{mm})$ & 0.035 & $\mathrm{Ts}(\mathrm{mm})$ & 1.575 \\
\hline material & Copper & material & Roger $(\varepsilon \mathrm{r}=2.2)$ \\
\hline
\end{tabular}




\subsection{Proposed FSS unit cell}

The proposed cell is a $0.035 \mathrm{~mm}$ copper hexagonal-loop was designed and fabricated on 1.575 $\mathrm{mm}$ thickness ROGGER substrate with dielectric constant is 2.2 as shown in figure 2 . It behave as passive electromagnetic filters and it selectively reflecting a desired frequency band to improve the gain, efficiency and resonant frequency of the patch antenna. The FSS response is determined by shape and dimension of the unit cell, in addition to the permittivity of substrate can control the bandwidth and resonance of FSS. Detail dimensions of the hexagonal loops ring element are evaluated as shown in table 2 .

Table 2. FSS unit cell parameters (mm)

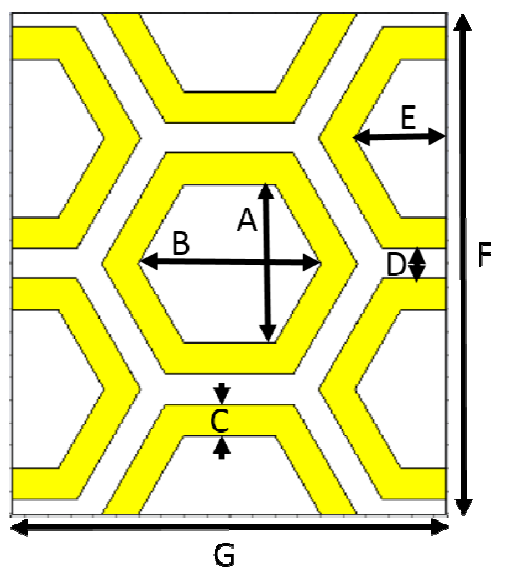

\begin{tabular}{|c|c|}
\hline Symbol & mm \\
\hline A & 9.7 \\
\hline B & 8 \\
\hline C & 0.8 \\
\hline D & 1.3 \\
\hline E & 4 \\
\hline F & 19 \\
\hline G & 22 \\
\hline
\end{tabular}

Figure 2: structure of proposed

FSS cells (truncated edge) printed on 40mm X 40mm Rogger substrate as shown in figure 3(a). FSS structure is placed on top of the proposed rectangular patch antenna as shown in figure.5, the FSS layer placed at separation $(\mathrm{H})$ is one over twenty of wavelengths to validate the compact size of the antenna. 


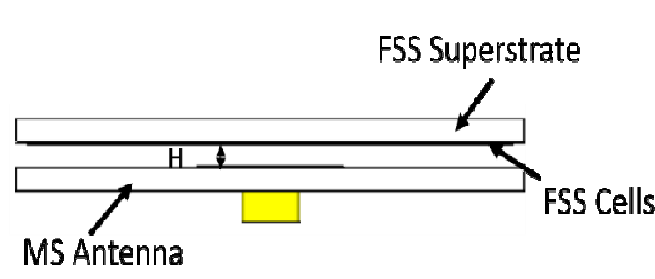

(a)

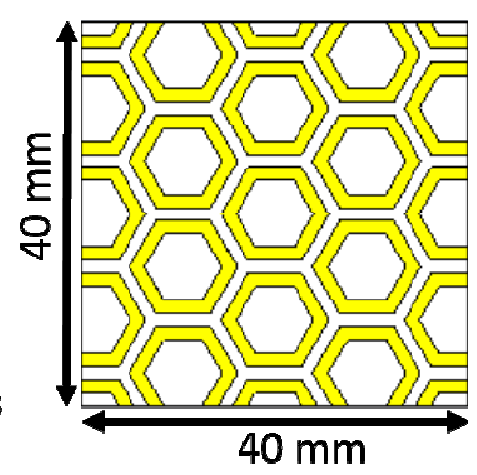

(b)

Figure 3: (a) proposed FSS Cells (b) structure of proposed antenna module

\section{RESULTS AND DISCUSSION}

In this section, a proposed FSS unit cell and the microstrip patch antenna, have been analyzed and simulated using the CST-MW simulator. CST stands for Computer Simulation Technology and consists of Microwave Studio, EM Studio, PCB Studio, etc. We focus on the Microwave Studio which employs the Finite Difference Time Domain Method. The method is based on the time domain and can cover a wide frequency band with one single simulation run. It is also quick and suitable for non-uniform models. However, results from CST do not closely fit for configurations with a large range of dimensions, such as a half wavelength dipole using an impractically thin wire for example. This is because of CST's sensitivity to extremely small mesh grid settings. A parametric study of FSS unit cell have been investigated as shown in figures [4], [5], and [6].

\subsection{UNITE CELL SIMULATION AND RESULTS}

Fig.4 shows the effect of changing modes on transmission and reflection coefficient characteristics of the proposed FSS unit cell. It is a band stop filter and it rejects wide band from $4 \mathrm{GHz}$ to $14 \mathrm{GHZ}$ with center frequency $10 \mathrm{GHz}$ at TE and TM mode. 
International Journal of Antennas (JANT) Vol.2, No.1, January 2016
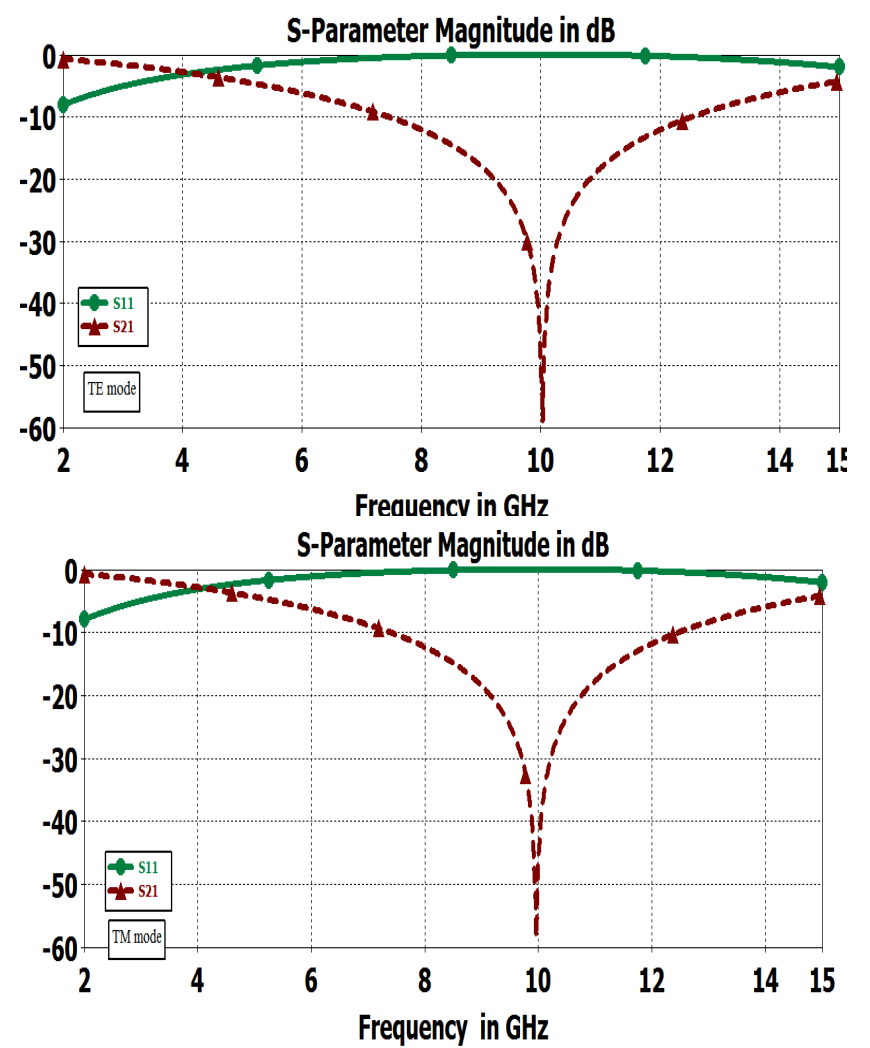

(a)

(b)

Figure 4: response of proposed unite cell in (a) TE mode and (b) TM mode.

The equivalent circuit of the proposed FSS unit cell with characteristic impedance $\mathrm{Z}$ is shown in Fig.5(a).The introduced capacitances represent the gap between conductors in the FSS unit-cell, while the inductance represents the metallic parts forming the hexagonal loop shape.

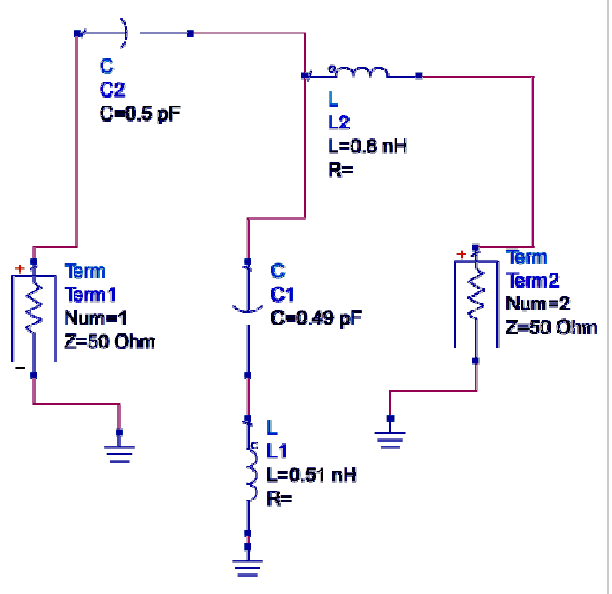




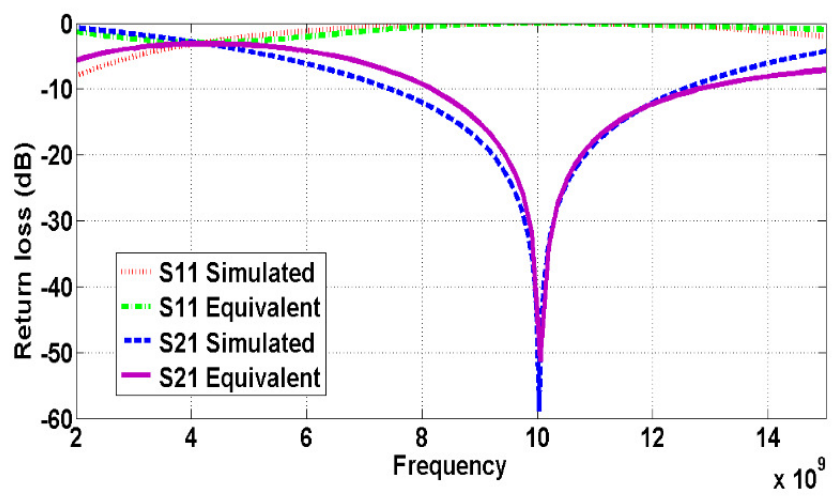

(a)

(b)

Figure 5: (a) equivalent circuit of proposed cell (b) frequency response of proposed cell and its equivalent circuit of unit cell.

For a proposed FSS unit cell geometry, an equivalent circuit (inductance and capacitance values) investigated. $\mathrm{C} 1=\mathrm{C} 2=0.49 \mathrm{pF}$ and $\mathrm{L} 1=0.51 \mathrm{nH} \mathrm{L} 2=0.8 \mathrm{nH}$, by changing the values of the inductances and capacitances, the resonance frequency is changed. Fig.5(b) shows the reflection and transmission characteristics of the equivalent circuit of proposed unit cell using ADS Software, two curves (proposed and its equivalent circuit) are almost identical. The filtering operation is affected by different parameter values such as spacing between loops (D), thickness of conductor $(\mathrm{C})$ of geometry and type of substrate material $\left(\varepsilon_{\mathrm{r}}\right)$.

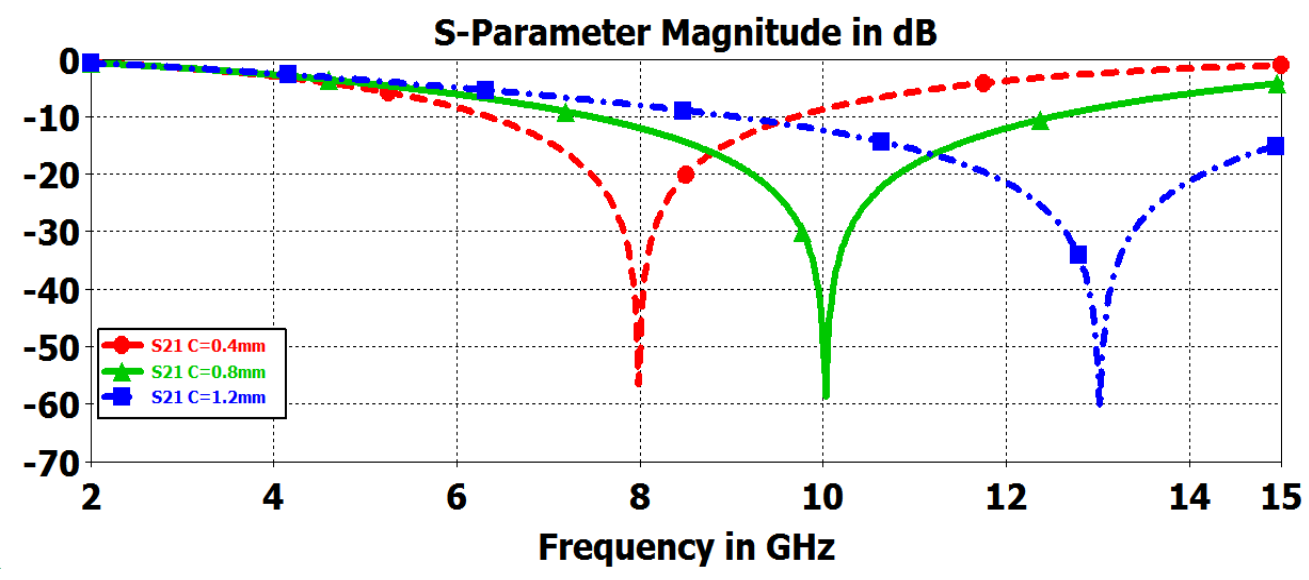

Figure 6: Effect of the changing conductor thickness "C" on the proposed FSS on the transmission coefficient.

Thickness of conductor has an important effect on the resonance of unit cell as shown in figure 6, as the thickness of conductor increase, the resonance frequency shifted toward higher frequency. 
International Journal of Antennas (JANT) Vol.2, No.1, January 2016

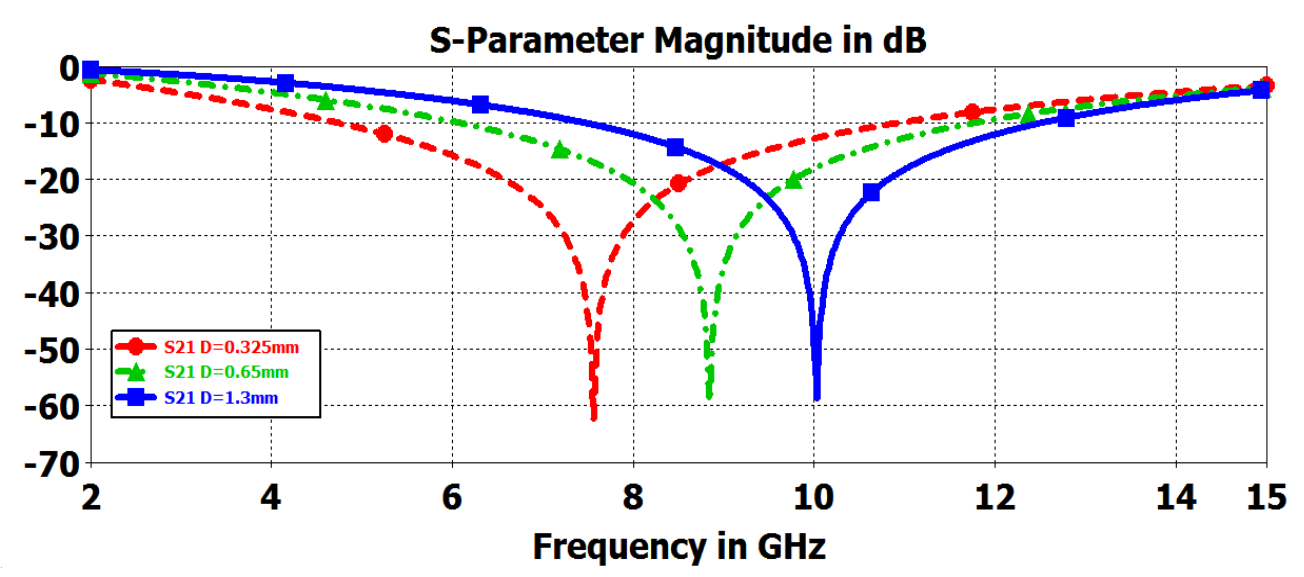

Figure 7: Effect of the changing spacing "D" on the proposed FSS on the transmission coefficient.

Figure.7 shows that the effect of changing space between loops each other, by increase the space "D" the frequency response shifted toward higher frequencies but bandwidth decrease. Bandwidth at "D" equal $1.3 \mathrm{~mm}$ is $5 \mathrm{GHz}$ and at "D" equal $0.325 \mathrm{~mm}$ bandwidth is $6.5 \mathrm{GHz}$.

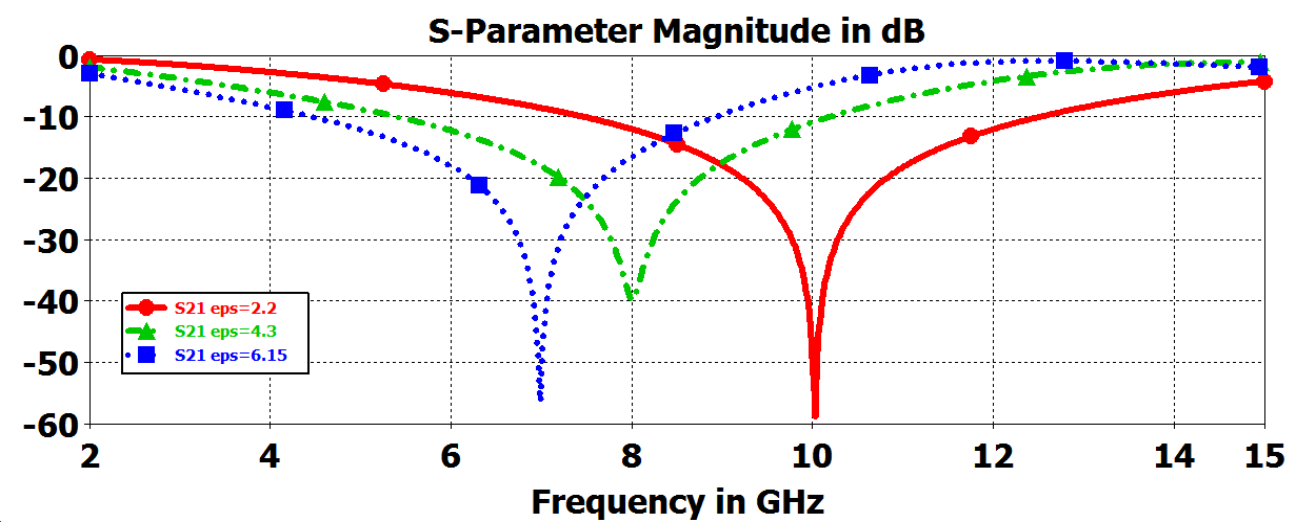

Figure 8: Effect of changing permittivity of the proposed FSS on the transmission coefficient.

The resonance frequency of the stop-band filter is also affected by the relative permittivity of the substrate. As illustrated in Figure 8, by increasing the substrate permittivity, the resonance frequency shifted to lower frequency that is allowed to operate at lower frequencies with the same compact size of FSS. 


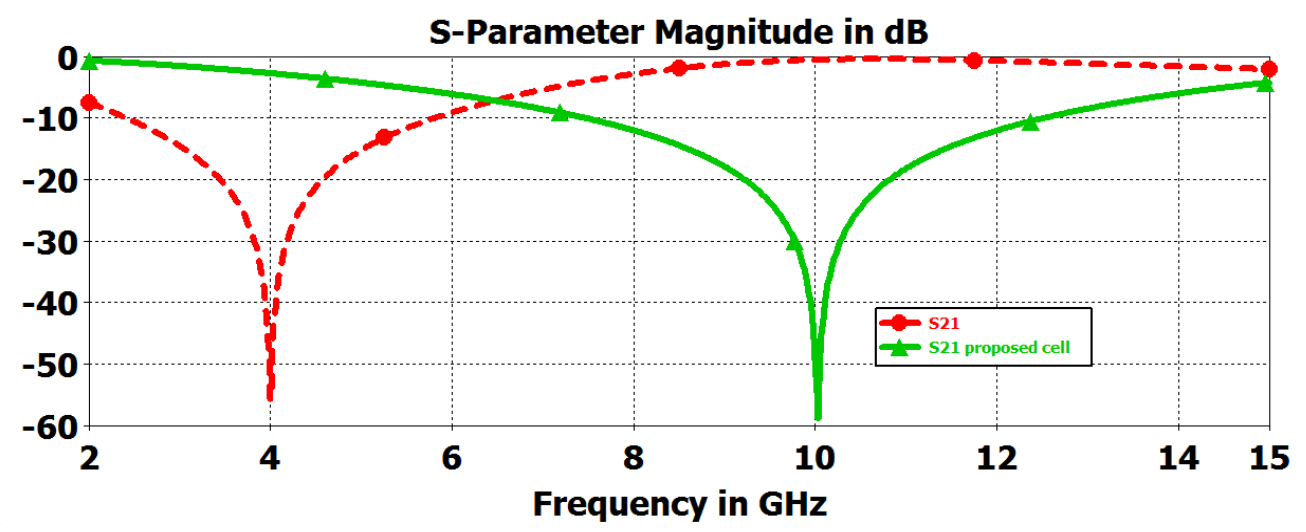

Figure 9: Transmission coefficients of FSS cell at $\mathrm{D}=0.325 \mathrm{~mm}, \mathrm{C}=0.4 \mathrm{~mm}$ and eps $=6.15$

As shown in figure 9, the smallest values of conductor thickness "C" and spacing " $D$ " and the highest permittivity have been used, so the frequency has been shifted to lowest value with the same compact size of FSS.

\subsection{Antenna and FSS simulation and results}

In this section, antenna implanted with and without FSS have been discussed. Figure.10 shows the return loss of antenna without FSS and with FSS at $\mathrm{H}=1.5 \mathrm{~mm}$ (separation between antenna and FSS), returned loss of antenna increase to $-16 \mathrm{~dB}$ and gain reached to 9.7 which has been improved by $48 \%$ and efficiency enhanced to reach $97 \%$ Final antenna results are listed in Table. 3

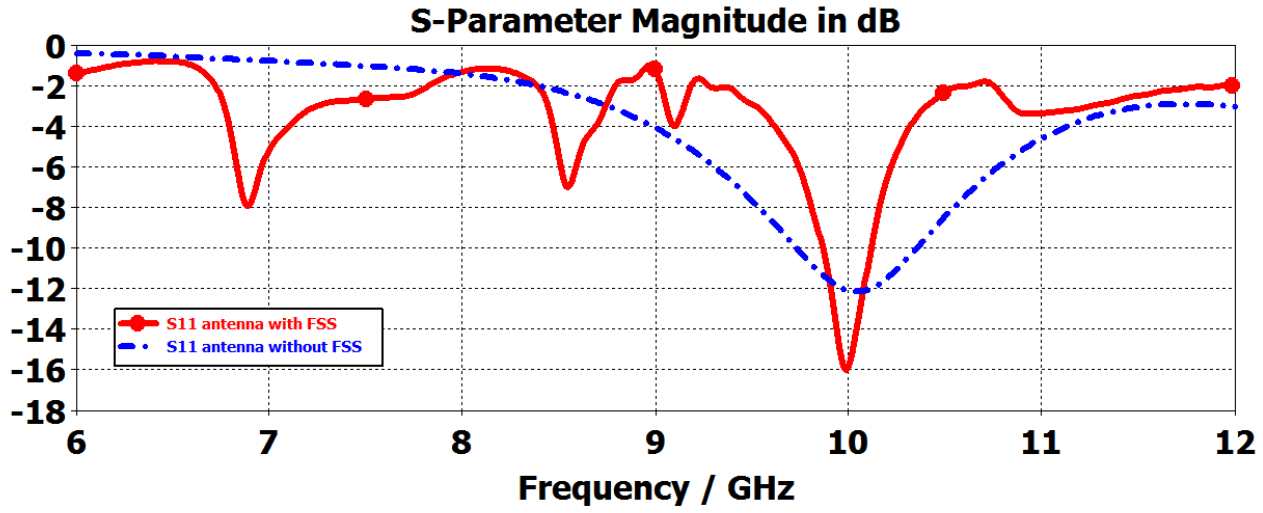

Figure 10: Return loss of antenna without FSS and with FSS at distance $\mathrm{H}=1.5 \mathrm{~mm}$ 
International Journal of Antennas (JANT) Vol.2, No.1, January 2016

Table. 3 final result of compact microstrip antenna

\begin{tabular}{|c|c|c|}
\cline { 2 - 3 } \multicolumn{1}{c|}{} & Without FSS & With FSS \\
\hline $\mathrm{F}_{\mathrm{r}}(\mathrm{GHz})$ & 10 & 10 \\
\hline $\mathrm{S}_{11}(\mathrm{~dB})$ & -12 & -16 \\
\hline BW $(\mathrm{MHz})$ & 600 & 250 \\
\hline Rad. Efficiency (\%) & 94.3 & 97 \\
\hline Gain $(\mathrm{dB})$ & 6.2 & 9.7 \\
\hline
\end{tabular}

Figure.11 shows effect of changing the separation $(\mathrm{H})$ between antenna and FSS, at distance $\mathrm{H}=0$. $375 \mathrm{~mm}$ a new resonance frequency appeared at $9.6 \mathrm{GHz}, 8 \mathrm{GHz}$ and $6.9 \mathrm{GHz}$. At separation $\mathrm{H}=1.5 \mathrm{~mm}$ only one resonance frequency appear at $10 \mathrm{GHz}$, so by decreasing separation between antenna and FSS that allow an antenna to resonate at new frequencies.

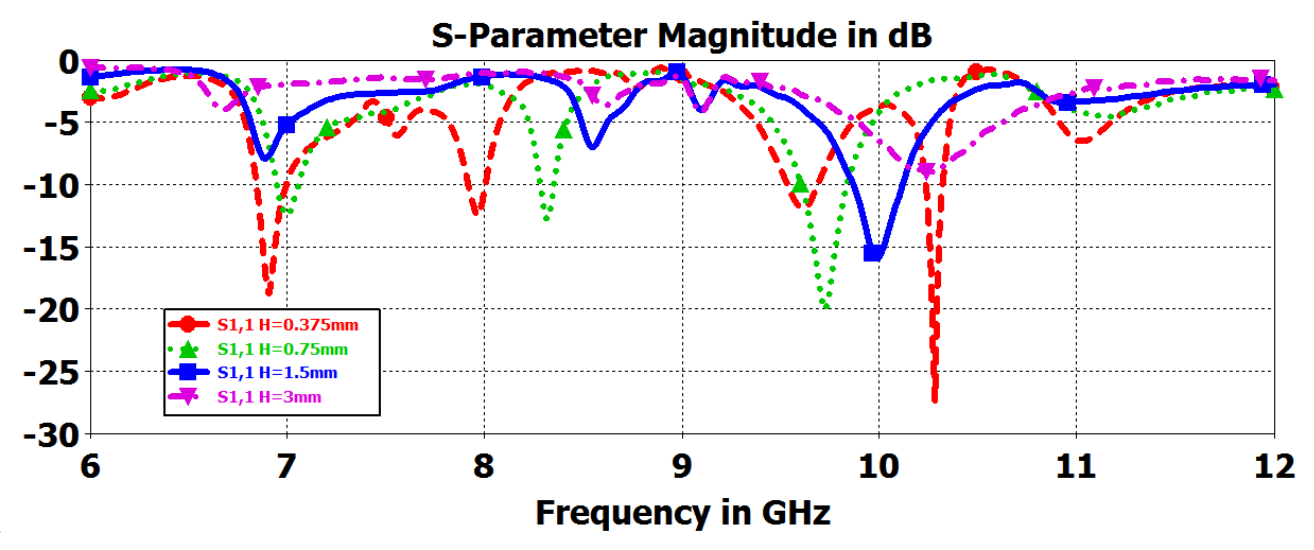

Figure 11: Effect of changing separation between antenna and FSS

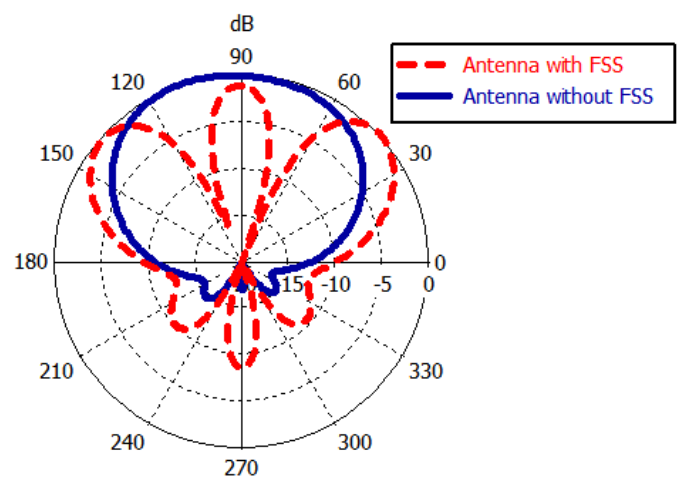

(a)

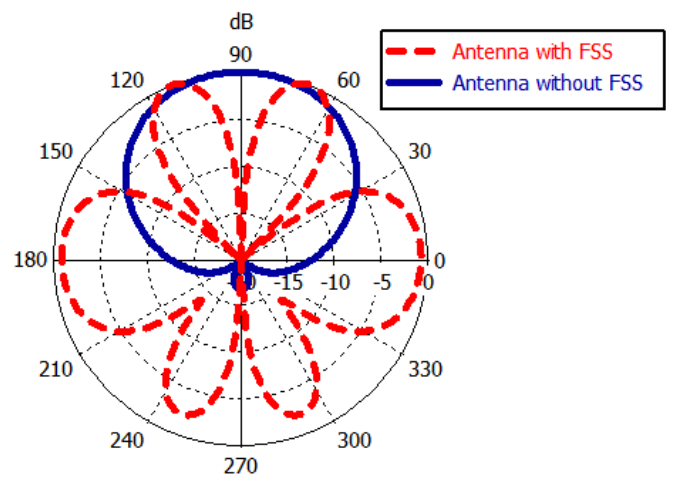

(b)

Figure12: Radiation patterns (a) E and (b) H planes 


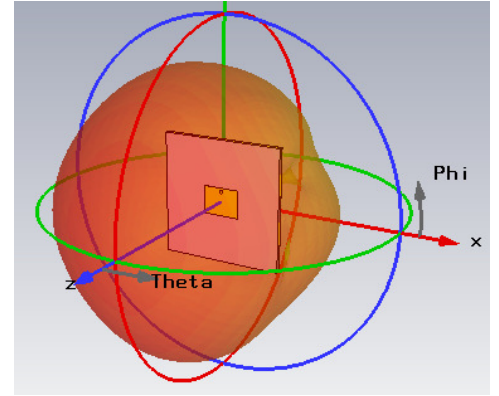

(a)

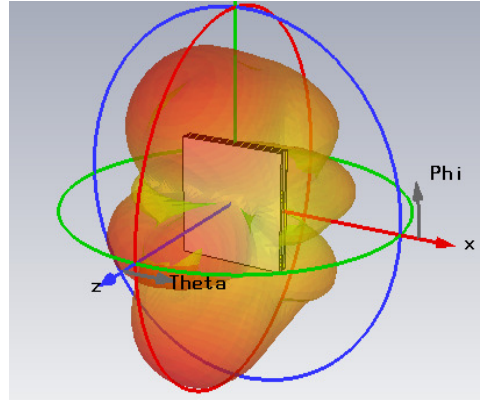

(b)

Figure 13: 3D Farfield pattern of antenna (a) without FSS and (b) with FSS

Fig. 12, 13 shows the radiation patterns of antenna with and without FSS at operating frequency $(10 \mathrm{GHz})$. The maximum gains levels have an obvious enhancement for the two main planes, along with an increase in the gains relative to that of the initial patch antenna. Before implanting FSS to MS antenna, the pattern was directive with a main loop at 90 degrees. After implanting FSS to antenna pattern shape has been changed. The pattern has been reshaped by FSS and it became multi-beam which it allowed to use antenna module in many applications such as scanning array.

\section{EXPERIMENTAL VERIFICATION}

The proposed antenna and FSS have been fabricated on an Rogger 5880 substrate with 1.575 thicknessas shown in Fig.14, and S11 of antenna with and without FSS have been measured and compared to the simulated results as presented in Fig. 15 and Fig. 16

Figure 15 shows the comparison between simulated and measured S11 for antenna only without FSS. It is noticed that the measured and simulated resonance frequencies are approximately identical. Figure 16 shows that a good agreement has been achieved between measured and simulated results and it is clear that the measured and simulated resonance frequencies are identical.

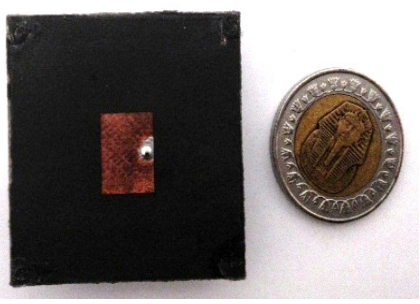

(a)
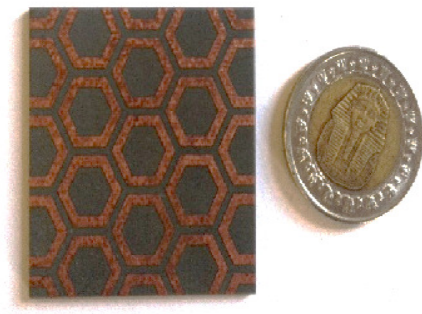

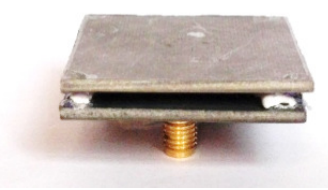

(b)

(c)

Figure.14 The prototype of (a) patch antenna and (b) FSS and (c) antenna module. 


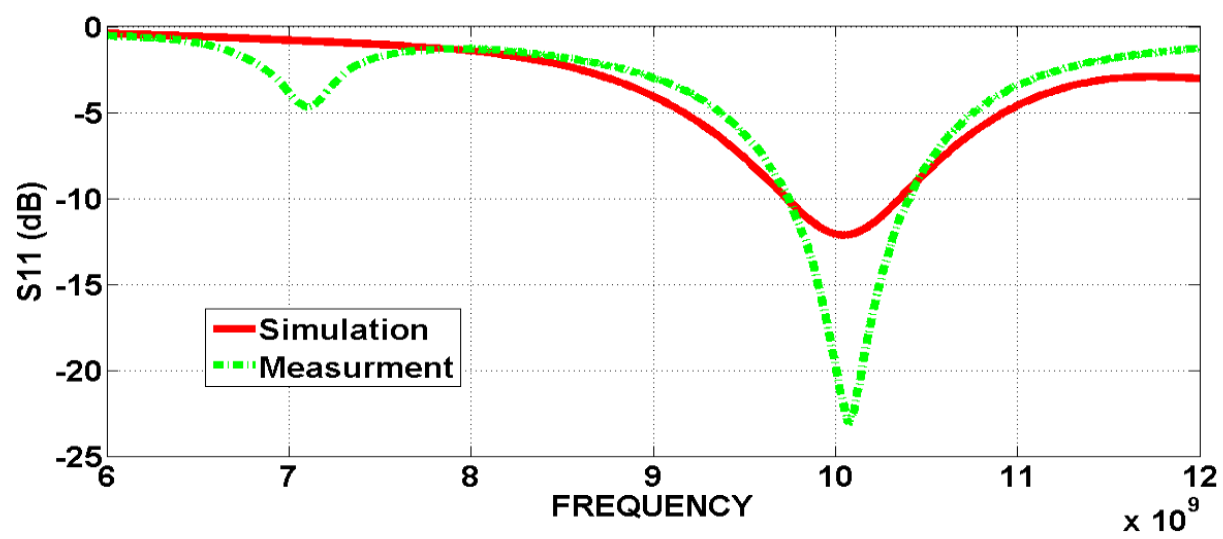

Figure.15 antenna without FSS simulation and Measured

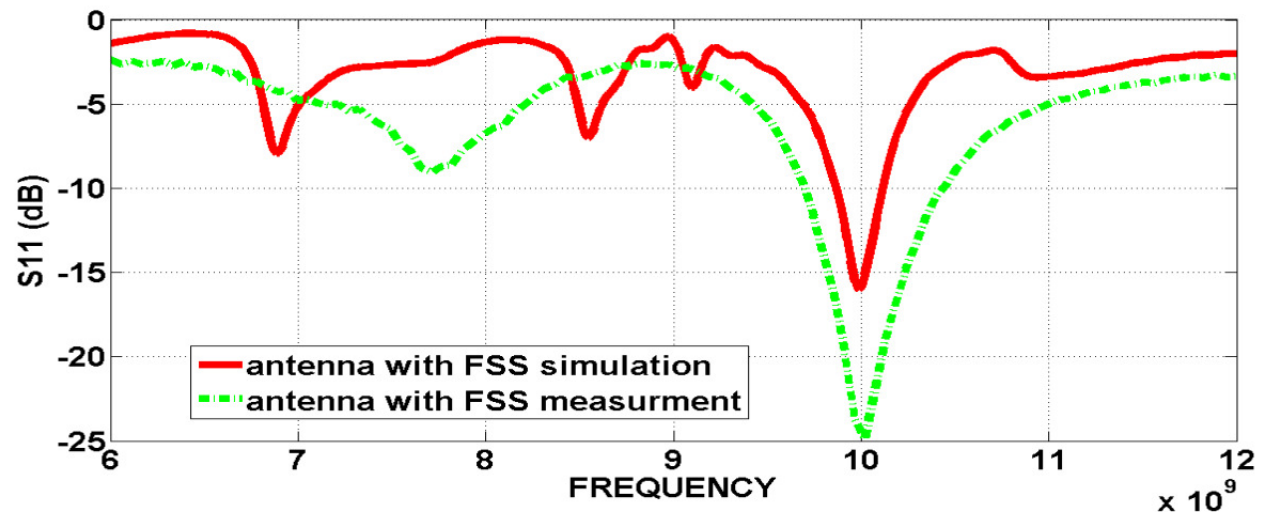

Figur3.16 antenna with FSS simulation and Measured

\section{CONCLUSION}

In this paper, high gain microstrip antenna is presented. From simulation results, it is found that the proposed FSS structure can be used as a stop band filter. The proposed FSS has been then applied as a superstrate to a conventional patch antenna to improve its gain and efficiency. The antenna and FSS has been implemented and tested. The measured return losses is in a reasonable agreement with the simulated results. The gain have been improved up to $9.2 \mathrm{~dB}$ (48\% increment) and efficiency increased to $97 \%$ at the operating frequency of $10 \mathrm{GHz}$. The radiation patterns at frequency $10 \mathrm{GHz}$ is acceptable. With these characteristics. The proposed antenna module (antenna and FSS) could be used in X-band applications.

\section{REFERENCES}

[1] Ramesh Garg, P.bahrtia “ Microstrip Antenna Design Handbook”, Artech House, London, 2000

[2] Constantine A. Balanis., "Antenna Theory: Analysis and Design”, Wiley-Interscience, New York, 2005

[3] K. Pengthaisong, P. Krachodnok, and R. Wongsan, "Design of a Dual-band Antenna using a Patch and Frequency Selective Surface for WLAN and WiMAX, "(ECTI-CON), International Conference. Krabi ,2013.

[4] S. Chaimool, K. L. Chung and P. Akkaraekthalin "SIMULTANEOUS GAIN AND BANDWIDTHS ENHANCEMENT OF A SINGLE-FEED CIRCULARLY POLARIZED MICROSTRIP PATCH ANTENNA USING A METAMATERIAL REFLECTIVE SURFACE” , Progress In Electromagnetics Research B, Vol. 22, 23-37, 2010. 
International Journal of Antennas (JANT) Vol.2, No.1, January 2016

[5] Karishma Sharma, Swati Vaid, and Ashok Mittal "An Investigation on High-Gain Dual-Polarized Cavity Reflex Antenna Using Slotted-Patch FSS Superstrate” 4th ICCCNT, Tiruchengode, India, July 2013.

[6] Aqeel H. Naqvi, Farooq A. Tahir "A Super Wideband printed antenna with enhanced gain using FSS structure "International Bhurban Conference on Applied Sciences \& Technology (IBCAST) Islamabad, Pakistan, 13th - 17th January, 2015.

[7] R.V.S. Ram Krishna and R. Kumar "Slotted ground microstrip antenna with FSS reflector for highgain horizontal polarization" ELECTRONICS LETTERS, Vol. 51 No. 8, 16th April 2015.

[8] Chen, H.-Y. and Y. Tao, "Bandwidth enhancement of a U-slot patch antenna using dual-band frequency-selective surface with double rectangular ring elements," Microwave Opt. Technol. Lett., Vol. 53, No. 7, Jul. 2011.

[9] Munk, A., "Frequency Selective Surfaces: Theory and Design", Wiley-Interscience, New York, 2000.

[10] Constantine A. Balanis., "MODERN ANTENNA HANDBOOK", Wiley-Interscience, New York, 2008.

[11] Da Silva, M. R., C. de L. N obrega, P. H. da F. Silva, and A. G. D'Assuncao, "Dual-polarized bandstop fss spatial filters using vicsek fractal geometry," Microwave Opt. Technol. Lett., Vol. 55, No. 1, Jan. 2013.

[12] H.Ghorbaninejad-Foumani and M.Khalaj-Amirhosseini, "COMPACT SPATIAL BAND-PASS FILTERS USING FREQUENCY SELECTIVE SURFACES” Progress in Electromagnetics Research C, Vol. 21, 2011.

[13] Sanjeev Yadav, Bhavana Peswani, Vandana Jain and M.M.Sharma "A Novel Miniaturized Compact Frequency Selective Surface Structure with Stable Resonance Characteristics ” (ICSPCT), 2014 International Conference, Ajmer, July 2014.

[14] M.R. Silva, C. L. Nóbrega, P. H.F. Silva, A. D. Assunção" Stable and compact multiband frequency selective surfaces with Peano pre-fractal configurations" IET Microwaves, Antennas \& Propagation, vol.7, 2013.

[15] R. Panwar, S. Puthucheri, V. Agarwala and D. Sing "Effect of Particle Size on Radar Wave Absorption of Fractal Frequency Selective Surface Loaded Multilayered Structures" IEEE International Microwave and RF Conference (IMaRC), Bangalore, Dec. 2014.

[16] Alireza Kazem Zadeh and Anders Karlsson "Capacitive Circuit Method for Fast and Efficient Design of Wideband Radar Absorbers" IEEE TRANSACTIONS ON ANTENNAS AND PROPAGATION, VOL. 57, NO. 8, AUGUST 2009

[17] F. Wang, W. Jiang, T. Hong, H. Xue, S. Gong and Y. Zhang "Radar cross section reduction of wideband antenna with a novel wideband radar absorbing materials " IET Microwaves, Antennas \& Propagation, , Vol. 8, Iss. 7, 2014.

[18] Arnaud, E., R. Chantalat, M. Koubeissi, T. Monediere, E. Rodes, and M. Thevenot, "Global design of an EBG antenna and meander-line polarizer for circular polarization," IEEE Antennas and Wireless Propagation Letters, Vol. 9, 215-218, 2011.

[19] Lin, H.-N., K.-W. Lin, and S.-C. Chen, "Use of frequency selective surfaces to prevent SAR and improve antenna performance of cellular phones," PIERS Proceedings",Sep, 2011. 